\title{
AVALIAÇÃO DO REAL POTENCIAL INIBIDOR DE EXTRATOS ETANÓLICOS DE Ottonia martiana SOBRE Cylindrocladium spathulatum E Botrytis cinerea
}

\author{
Miriam Machado Cunico ${ }^{1}$, Celso Garcia Auer ${ }^{2}$, Marlon Wesley Machado Cunico ${ }^{3}$, \\ Obdulio Gomes Miguel ${ }^{4}$, Patrício Alberto Peralta-Zamora ${ }^{5}$, Carlos Roberto Sanquetta ${ }^{6}$ \\ ${ }^{1}$ Química, Dra ., Concep3D Pesquisas Científicas, Curitiba, PR, Brasil - miriammcunico@gmail.com \\ ${ }^{2}$ Eng. Florestal, Dr., Laboratório de Patologia Florestal, Embrapa Florestas, Colombo, PR, Brasil - celso.auer@embrapa.br \\ ${ }^{3}$ Eng. Mecânico, Dr., Concep3D Pesquisas Científicas, Curitiba, PR, Brasil - marloncunico@gmail.com \\ ${ }^{4}$ Químico, Dr., Depto. de Farmácia, UFPR, Curitiba, PR, Brasil - obdulio@ufpr.br \\ ${ }^{5}$ Químico, Dr., Depto. de Química, UFPR, Curitiba, PR, Brasil - zamora@ufpr.br \\ ${ }^{6}$ Eng. Florestal, Dr., Depto. de Ciências Florestais, UFPR, Curitiba, PR, Brasil - sanquetta@ufpr.br
}

Recebido para publicação: 14/12/2010 - Aceito para publicação: 02/04/2013

\begin{abstract}
Resumo
Extratos etanólicos de anestesia, Ottonia martiana Miq., foram reavaliados quanto à inibição do crescimento micelial dos fungos Cylindrocladium spathulatum (pinta-preta da erva-mate) e Botrytis cinerea (mofo-cinzento do eucalipto), por meio do planejamento fatorial. A ocorrência de decomposição de bioativos no processo de autoclavagem também foi investigada, por meio de teste de eficiência de extratos filtrados (filtro Millipore) e esterilizados (autoclave) no controle dos fitopatógenos, nas concentrações de 1, 10, 100 e $1000 \mathrm{ppm}$. Os extratos etanólicos filtrado e esterilizado inibiram o crescimento micelial dos fungos e foram mais ativos frente a $B$. cinerea. $\mathrm{O}$ extrato filtrado exibiu maior potencial antifúngico que o extrato esterilizado. O processo de esterilização por autoclavagem causou pequena decomposição dos bioativos presentes no extrato de anestesia.

Palavras-chave: Anestesia; mofo-cinzento; pinta-preta.
\end{abstract}

\begin{abstract}
Fungitoxic potential of ethanolic extracts of anestesia in the control of phytopathogenic diseases. The antifungal potential of anestesia, Ottonia martiana Miq. was reassessed by factorial design, in vitro testing of fungal mycelial growth compared to the pathogenic isolates Cylindrocladium spathulatum, causal agent of black spot on yerba mate, and Botrytis cinerea causal agent of gray-mold on eucalypts. Occurrence of decomposition of bioactive of the autoclaving process was investigated using foliar detached test compared to the pathogens (1000 ppm). Ethanolic extracts - EBEtOH (filtered and autoclaved) inhibited the mycelial growth of $C$. spathulatum and B. cinerea (1000 ppm) and were more pronounced against $B$. cinerea (43.6\% and $68.9 \%)$. EBEtOH filtered $(0.22 \mu \mathrm{m})$ presented higher activity than $\mathrm{EBEtOH}$ autoclaved (C. spathulatum: $52.8 \%$ and $43.6 \%$, B. cinerea: $68.9 \%$ and $43.6 \%$ ), suggesting little decomposition of bioactive after autoclaving. EBEtOH filtrate presented potential inhibition of $28 \%$ in eucalypt leaves against $B$. cinerea.

Keywords: Ottonia martiana; black spot; gray-mold.
\end{abstract}

\section{INTRODUÇÃO}

O manejo da pinta-preta e do mofo-cinzento, doenças que ocorrem em viveiros de mudas florestais como o eucalipto (Eucalyptus spp.) e a erva-mate (Ilex paraguariensis), respectivamente, têm sido objeto de estudos, incluindo a busca por alternativas naturais de controle em substituição aos produtos sintéticos existentes (CUNICO et al., 2006). Pesquisas recentes têm mostrado que extratos vegetais apresentam ação fungitóxica, despertando grande interesse científico no emprego de plantas no controle alternativo de fitopatógenos (VENTUROSO et al., 2011; PERINI et al., 2013). A exploração da atividade biológica de compostos secundários presentes no extrato bruto ou óleo essencial de plantas 
medicinais pode constituir, ao lado da indução de resistência, mais uma forma potencial de controle alternativo de doenças em plantas cultivadas, segundo Schwan-Estrada et al. (2000).

O Brasil é detentor da maior biodiversidade conhecida, com aproximadamente $30 \%$ das florestas tropicais do mundo, apresentando cerca de 200 mil espécies vegetais, das quais $40 \%$ apresentam propriedades medicinais (BRESOLIN; CECHINEL FILHO, 2007). Contudo, mesmo com essa grande biodiversidade, menos de $1 \%$ dessa flora foi pesquisada quimicamente (ELISABETSKY; COSTACAMPOS, 1996). Isso indica a necessidade de intensificar os estudos fitoquímicos, com o intuito de descobrir as propriedades e os bioativos dessas espécies vegetais.

Na Floresta Ombrófila Densa, Bioma Mata Atlântica, espécies da família Piperaceae têm se destacado na produção de extratos de ação fungitóxica, podendo-se citar a anestesia (Ottonia martiana Miq.), arbusto característico da Floresta Atlântica brasileira. Segundo os nativos do litoral paranaense, essa planta tem ação anestésica local e por isso tem sido utilizada popularmente no tratamento de odontalgias, na forma in natura (mastigação) ou de alcoolaturas (bochechos). Estudos fitoquímicos resultaram no isolamento e identificação das amidas piperovatina, isopiperovatina, piperlonguminina e isopiperlonguminina (CUNICO et al., 2005). Sua ação antifúngica foi posteriormente relatada por Cunico et al. (2007).

O presente trabalho apresenta como principal objetivo a avaliação do efeito de variáveis de relevância no potencial antifúngico dos extratos etanólicos de $O$. martiana sobre dois fitopatógenos, recorrendo-se a sistemas de planejamento fatorial de experimentos. Para comparação, o efeito da concentração do extrato e do tipo de pré-tratamento (filtração ou autoclavagem) também foi avaliado de maneira univariada.

\section{MATERIAL E MÉTODOS}

\section{Obtenção do material vegetal}

Raízes, caules, folhas e frutos de O. martiana foram coletadas em fevereiro de 2002, no município de Guaratuba (encosta da Floresta Atlântica, Serra do Mar), Paraná, a uma altitude de $20 \mathrm{~m}$ em relação ao nível do mar. A identificação da espécie botânica foi realizada pelo Dr. Gerdt Hatschbach, do Museu Botânico Municipal (MBM) da Prefeitura de Curitiba, Paraná. A exsicata encontra-se depositada no herbário do MBM, catalogada e registrada sob o nº 259.057.

\section{Obtenção dos extratos vegetais}

Raízes, caules, folhas e frutos secos $(700 \mathrm{~g})$ de $O$. martiana foram moídos e submetidos a tripla maceração a frio, 3 vezes por 7 dias, em etanol a 95\%. Após filtração, o extrato etanólico foi concentrado em evaporador rotatório Büchi sob pressão reduzida $\left(30 \mathrm{mmHg}, 40{ }^{\circ} \mathrm{C}\right)$, colocado em frasco âmbar e conservado em freezer por 24 horas, para precipitação de pigmentos, e filtrado novamente a vácuo. $\mathrm{O}$ extrato bruto etanólico final obtido com concentração de $32,9 \mathrm{mg} \cdot \mathrm{mL}^{-1}$ foi denominado EBEtOH.

\section{Avaliação da atividade antifúngica}

Para a avaliação da atividade do EBEtOH sobre crescimento micelial de dois fitopatógenos, o extrato precisou ser esterilizado, para não ocorrer contaminação do meio de cultura com outros microrganismos. Assim, uma parte do EBEtOH foi esterilizada em autoclave $\left(120^{\circ} \mathrm{C}, 1 \mathrm{~atm}, 15\right.$ minutos $)$ juntamente com o meio de cultura comercial BDA (batata-dextrose-ágar; $39 \mathrm{~g}$ do produto, água destilada, $1000 \mathrm{~mL}$ ), vertidos em placas de Petri, com $15 \mathrm{~mm}$ de diâmetro. A outra parte do extrato foi filtrada em membrana Millipore $(0,22 \mu \mathrm{m})$ e colocada posteriormente no meio de cultivo fundente, após a autoclavagem do meio. Os fitopatógenos testados foram Cylindrocladium spathulatum e Botrytis cinérea, pertencentes à coleção de fungos florestais patogênicos da Embrapa Florestas, Colombo, PR.

Neste ensaio, avaliou-se o potencial antifúngico do EBEtOH de $O$. martiana sobre o crescimento micelial de $C$. spathulatum e B. cinerea, seguindo-se procedimento descrito por Cunico et al. (2006).

Os extratos EBEtOH filtrado e autoclavado foram incorporados ao meio de cultura, para se obterem concentrações finais de 1, 10, 100 e 1000 ppm. Discos de micélio-ágar com cinco mm de diâmetro de $C$. spathulatum e $B$. cinerea, retirados das culturas puras com sete dias de idade, em meio BDA, foram transferidos isoladamente para o centro de cada placa. As placas foram vedadas com filme PVC e incubadas a $25^{\circ} \mathrm{C}$, no escuro. Como controle positivo de crescimento micelial, utilizou-se apenas 
o meio BDA, e como controle negativo, o fungicida benomyl foi incorporado ao meio BDA, para se obterem as concentrações finais de $1,10,100$ e 1000 ppm.

O delineamento experimental foi inteiramente casualizado, com cinco repetições. As avaliações foram realizadas por meio da medição do diâmetro das colônias (média de duas medidas perpendiculares), no momento em que as colônias fúngicas do controle de crescimento micelial atingiram aproximadamente a superfície total do meio de cultura.

\section{Uso do planejamento fatorial para análise do efeito do extrato}

Em função da possibilidade de ocorrer decomposição de bioativos do extrato no processo de esterilização por autoclavagem, realizou-se um teste para comparar o potencial antifúngico do extrato filtrado e autoclavado, por meio de planejamento fatorial $2^{2}$, sem pontos centrais e com três repetições. Foram consideradas como variáveis independentes a concentração do extrato (10 e $1000 \mathrm{ppm})$ e o processo de produção do extrato (filtrado ou autoclavado), enquanto para a variável dependente (resposta) foi considerada a inibição do crescimento micelial. A faixa de interesse experimental (níveis inferior e superior) de cada fator foi determinada considerando o potencial fungitóxico obtido com diferentes concentrações dos extratos filtrado e autoclavado, com base no crescimento micelial e decomposição de bioativos, respectivamente.

O planejamento fatorial foi processado no programa estatístico Minitab "for Windows" (MINITAB, 2003). A relevância dos efeitos foi avaliada por comparação com os valores do erro padrão dos efeitos $\left(S^{2}\right)$, calculados de acordo com:

$$
\begin{gathered}
\left.S^{2}(\text { efeito })=4 / N S^{2} \text { (experimental }\right) \\
\text { Efeito significativo }>t S
\end{gathered}
$$

Em que: $S^{2}=$ corresponde à estimativa da variância;

$N=$ ao número de ensaio do planejamento;

$t=$ ao ponto de distribuição para o nível de confiança desejado.

\section{RESULTADOS E DISCUSSÃO}

\section{Influência do EBEtOH sobre o crescimento micelial}

Inicialmente, foi avaliado o efeito da concentração do EBEtOH de Ottonia martiana no crescimento micelial de $C$. spathulatum e $B$. cinerea, utilizando-se extratos autoclavados. Foi verificado que o crescimento micelial somente foi inibido para os dois fungos, principalmente para $B$. cinerea (Figura 1A), com o uso da maior concentração avaliada (1000 ppm). Nessa concentração, a inibição do controle positivo (benomyl) foi de $86,5 \%$ para $B$. cinerea e de $100 \%$ para $C$. spathulatum, mostrando ser mais efetivo para o controle do crescimento desses fungos.

Em seguida, foi avaliado o efeito do pré-processamento (filtração e autoclavagem) na atividade antifúngica do extrato, utilizando EBEtOH em concentração de $1000 \mathrm{ppm}$. O extrato filtrado $(49,6 \%)$ apresentou potencial antifúngico maior frente a $C$. spathulatum do que o extrato autoclavado $(40,4 \%)$, conforme pode ser visto na figura 1B. Várias pesquisas mostram que extratos de outras plantas podem inibir o crescimento micelial desse patógeno. Quirino et al. (2000) mostraram que extrato aquoso bruto de Myrciaria tenella incorporado ao meio BDA inibiu o crescimento micelial de C. spathulatum em 66,9\%. Em um teste de bioautografia direta com EBEtOH de caules e folhas de Aster lanceolatus, também houve inibição na germinação e posterior crescimento micelial de C. spathulatum (DIAS et al., 2006).

Para B. cinerea, houve também maior inibição do crescimento com o extrato filtrado $(64,3 \%)$ comparado com o extrato autoclavado (42,6\%), conforme figura 1A. Estudo com óleos essenciais de capim-limão e palmarosa na dose de $1000 \mathrm{ppm}$ apresentaram efeito fungicida (100\% de controle), impedindo o crescimento do patógeno (LORENZETTI et al., 2011). Fogolari (2010) verificou que extrato aquoso (macerado em água) de calêndula em todas as suas concentrações inibiu o crescimento do fungo B. cinerea in vitro, sendo que, a partir de $2,5 \%$, observou-se inibição total. $\mathrm{O}$ autor verificou também que o tratamento com infusão na sua maior concentração (10\%) também apresentou resposta positiva na inibição do crescimento do patógeno. Esses trabalhos indicam que os extratos ou óleos essenciais podem ser bem aplicados para o controle do desenvolvimento desses patógenos. 
A decomposição de parte de bioativos no processo de autoclavagem fica evidenciado, corroborando estudo similar realizado por Cunico et al. (2005), que constatou alterações no perfil cromatográfico do extrato aquoso autoclavado dessa espécie vegetal, por meio de análise cromatográfica (CLAE).
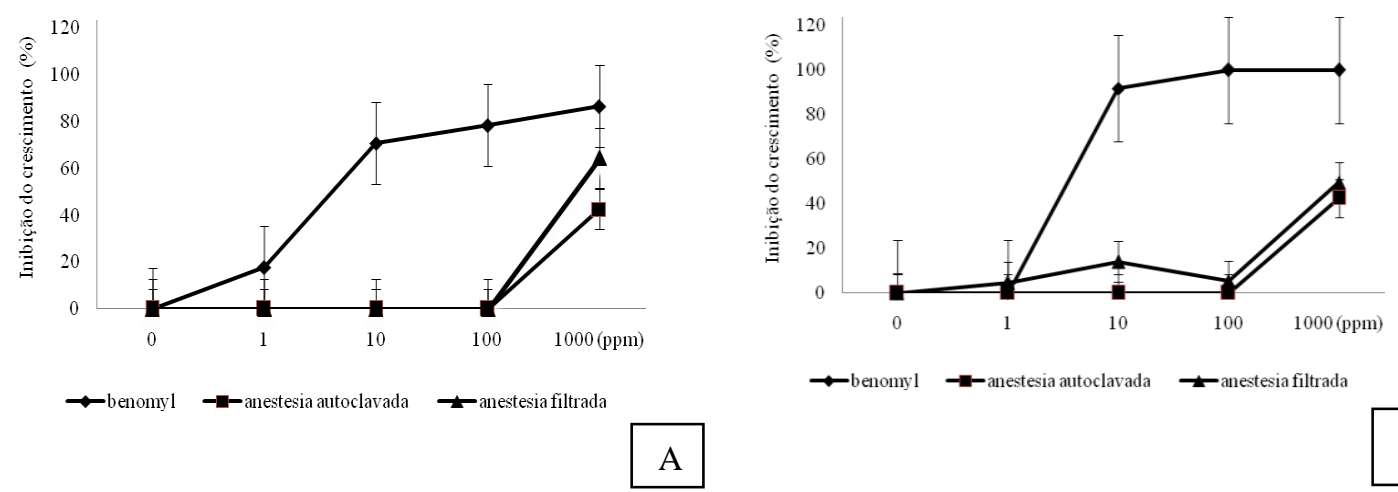

\section{A}

Figura 1. Efeito da concentração do extrato de Ottonia martiana na inibição do crescimento micelial de Botrytis cinerea (A) e Cylindrocladium spathulatum (B).

Figure 1. Results of factorial design $2^{2}$ of comparing study of the potential of extracts from Ottonia martiana Miq. (Answer: inhibition (\%) of mycelial growth).

\section{Planejamento fatorial}

Calculando-se os efeitos da maneira tradicional (BOX et al., 1978), é possível observar um forte efeito positivo da concentração (31 pontos percentuais), o que confirma a elevada capacidade antifúngica do extrato quando em elevadas concentrações (Tabela 1). Por outro lado, o efeito do pré-tratamento é negativo (-33), o que demonstra claramente um efeito contraproducente da autoclavagem sobre o potencial antifúngico avaliado.

Em função desses efeitos, a maior capacidade de inibição corresponde às condições do experimento 2 (aproximadamente 64\% de inibição). Entretanto, a existência de um efeito de segunda ordem $(\mathrm{C} \times \mathrm{P}=12)$ implica que o efeito de uma variável depende da magnitude da segunda variável, o que pode ser visualizado na representação geométrica apresentada na figura 2 . Analisando-se o efeito da concentração do extrato filtrado na inibição do crescimento micelial fúngico, é possível perceber que o percentual de inibição aumenta 18 pontos percentuais quando a concentração aumenta de 10 para 1000 ppm. Fazendo-se essa análise em relação ao extrato autoclavado, percebe-se que idêntico aumento na concentração do extrato provoca um aumento muito mais significativo na inibição medida (43), o que necessariamente implica um efeito de interação entre variáveis. Essa observação indica que o processo de autoclavagem é nitidamente mais prejudicial para a atividade antifúngica dos extratos utilizados em baixa concentração. Por sua vez, sugere efeitos pouco significativos da autoclavagem quando se utilizam extratos em concentração acima de 1000 ppm.

Tabela 1. Resultados do planejamento fatorial $2^{2}$ do estudo comparativo do potencial dos extratos de Ottonia martiana Miq. (Resposta: inibição (\%) do crescimento micelial dos fungos testados).

Table 1. Results of factorial design $2^{2}$ study comparing the potential of extracts from Ottonia martiana Miq. (Answer: inhibition (\%) of mycelial growth).

\begin{tabular}{|c|c|c|c|c|c|c|}
\hline \multicolumn{4}{|c|}{ Variável } & \multicolumn{2}{|c|}{ Nível (-) } & Nível (+) \\
\hline \multicolumn{4}{|c|}{$\begin{array}{c}\text { Concentração }(C) \\
\text { Pré-processamento (P) }\end{array}$} & $\begin{array}{r}10 \mathrm{p} \\
\text { Filtra }\end{array}$ & & $\begin{array}{l}000 \text { ppm } \\
\text { clavado (A) }\end{array}$ \\
\hline \multirow{2}{*}{ Ensaio } & \multicolumn{3}{|c|}{ Variáveis } & \multicolumn{3}{|c|}{ Resposta } \\
\hline & $C$ & $\mathbf{P}$ & $C \times P$ & $\mathbf{R}_{1}$ & $\mathbf{R}_{2}$ & $\mathbf{R}$ \\
\hline 1 & - (10) & - (F) & + & 45,59 & 45,61 & $45,60 \pm 0,01$ \\
\hline 2 & $+(1000)$ & $-(\mathrm{F})$ & - & 63,92 & 63,94 & $63,93 \pm 0,01$ \\
\hline 3 & $-(10)$ & $+(\mathrm{A})$ & - & 0,58 & 0,60 & $00,59 \pm 0,01$ \\
\hline 4 & $+(1000)$ & $+(\mathrm{A})$ & + & 43,57 & 43,59 & $43,58 \pm 0,01$ \\
\hline
\end{tabular}

Efeitos principais: $C[(-45,60+63,93-0,59+43,58) / 2]=+30,66 \pm 0,01 ; \mathrm{P}[-45,60-63,93+0,59+43,58) / 2]=-32,68 \pm 0,01$

Efeitos de segunda ordem: $C \mathrm{xP}[(+45,60-63,93-0,59+43,58) / 2]=+12,33 \pm 0,01$ 
Evidenciar a interação entre variáveis representa a principal diferença entre sistemas univariados convencionais e sistemas multivariados fundamentados em planejamento fatorial. Neste caso, a otimização preliminar sugere o uso de elevadas concentrações do extrato e desaconselha operações de autoclavagem. Por sua vez, o planejamento sugere que a autoclavagem pode ser utilizada, desde que a concentração do extrato seja elevada.

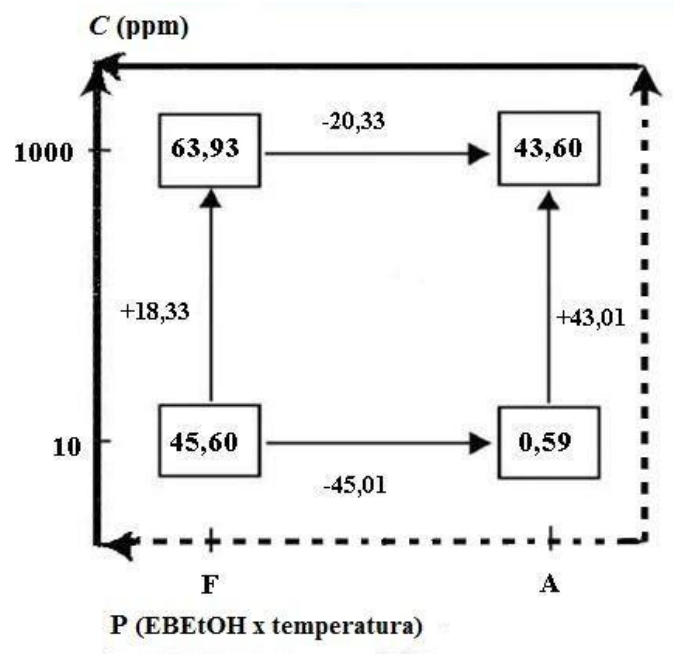

Figura 2. Representação geométrica do planejamento fatorial $2^{2}$ do sistema $C \times \mathrm{P}$ na comparação do potencial antifúngico dos extratos da Ottonia martiana Miq. (Resposta: \% de inibição do crescimento micelial).

Figure 2. Geometric representation of the factorial design $2^{2}$ of system $C \times \mathrm{P}$ in comparison of the antifungal potential of extracts from Ottonia martiana Miq. (Answer: \% inhibition of mycelial growth).

Como o sistema permite evidenciar as interações entre as variáveis estudadas, explicações são indispensáveis e devem ser fundamentadas em argumentos técnicos relacionados com o processo em estudo. Sendo assim, no presente trabalho, o favorecimento do processo de inibição do crescimento micelial fúngico evidenciado no extrato filtrado pode ser explicado pela possível ausência de decomposição dos principais bioativos. Cabe esclarecer que o extrato autoclavado também apresentou potencial antifúngico, porém menos pronunciado que aquele apresentado pelo extrato filtrado, indicando que boa parte dos bioativos permaneceram inalterados, ou seja, não sofreram decomposição pela ação da alta temperatura no processo de autoclavagem.

O potencial de inibição de crescimento micelial fúngico exibido pelo extrato filtrado indica a possibilidade de uso do EBEtOH de O. martiana para o controle alternativo desses dois fitopatógenos em viveiros florestais. De acordo com os resultados, o extrato deve ser utilizado sem que haja algum tipo de processamento térmico, para que não reduza sua capacidade de inibir o desenvolvimento dos fitopatógenos. Sabe-se que é a etapa inicial do uso dessa planta medicinal no controle de doenças de plantas, pois é necessário ainda conhecer a concentração mínima do extrato para aplicação em mudas visando o controle do mofo-cinzento do eucalipto e da pinta-preta da erva-mate.

\section{CONCLUSÕES}

Os extratos etanólicos de $O$. martiana (filtrado e autoclavado) inibiram o crescimento micelial dos fitopatógenos testados e a resposta de inibição foi dependente da dose de extrato colocada no meio de cultivo dos fungos. Comparando-se o potencial de inibição dos extratos, verificou-se que extrato filtrado foi maior do que o exibido pelo extrato esterilizado, contudo ambos não foram tão inibitórios como o fungicida benomyl. Analisando o efeito do processo de esterilização por autoclavagem, considerou-se que ele não degradou a maioria dos bioativos antifúngicos do extrato etanólico de $O$. martiana. 


\section{REFERÊNCIAS}

BOX, G. E. P.; HUNTER, W. G.; HUNTER, J. S. Statistics for experimenters: an introduction to design, data analysis, and model building. New York: John Wiley and Sons, 1978. 653 p.

BRESOLIN, T. M. B.; CECHINEL FILHO, V. Plantas medicinais e fitoterápicos: 12 anos de estudos realizados no NIQFAR/UNIVAL. Revista Elofar Vida, Florianópolis. p: 13 - 16, 2007.

CARDOSO FILHO, J. A. Efeito de extratos de albedo de laranja (Citrus cinensis) dos indutores de resistência ácido salicílico, acilbenzolar-s-metil e Saccharomyces cerevisiae no controle de Phyllosticta citricarpa (teleomorfo: Guignardia citricarpa). $126 \mathrm{f}$. Tese (Doutorado em Agronomia) Universidade de São Paulo, Piracicaba, 2003.

CUNICO, M. M.; CARVALHO, J. L. S.; AUER, C. G.; GRIGOLLETI JÚNIOR, A.; MONACHE, F. D.; MIGUEL, M. D.; MIGUEL, O. G. Gênero Ottonia: uma revisão das principais características botânicas, fitoquímicas e biológicas. Revista Brasileira de Plantas Medicinais, Botucatu, v. 7, n. 2, p. 17 - 21, 2005.

CUNICO, M. M.; CARVALHO, J. L. S.; ANDRADE, C. A.; MIGUEL, O. G.; MIGUEL, M. D.; AUER, C. G.; GRIGOLETTI JÚNIOR, A.; COCCO, L. C.; YAMAMOTO, C. I. Atividade antifúngica de extratos brutos de Ottonia martiana Miq., Piperaceae. Visão Acadêmica, Curitiba, v. 7, n. 2, p. 53 - 60. 2006.

CUNICO, M. M.; LOPES, A. R.; COCCO, L. C.; YAMAMOTO, C. I.; MIGUEL, M. D.; GRIGOLLETI JÚNIOR, A.; AUER, C. G.; MIGUEL, O. G. Phytochemical and antibacterial evaluation of essential oils from Ottonia martiana Miq. Journal of the Brazilian Chemical Society, São Paulo, v. 18, n. 1, p. 184 188, 2007.

DIAS, J. F. G.; VIRTUOSO, S.; DAVET, A.; CUNICO, M. M.; MIGUEL, M. D.; AUER, C. G.; OLIVEIRA, A. B.; FERRONATO, M. L. Atividade antibacteriana e antifúngica de extratos etanólicos de Aster lanceolatus Willd., Asteraceae. Revista Brasileira de Farmacognosia. Curitiba, v. 16, p. 83 - 87, 2006.

ELISABETSKY, E.; COSTA-CAMPOS, L. Medicinal plant genetic resources and international cooperation: the Brazilian perspective. Journal of Ethnopharmacology, Chicago, v. 51, p. 111 - 120, 1996.

FOGOLARI, H. Potencial de extratos à base de Calendula officinalis L. na indução de resistência e no efeito fungistático sobre Botrytis cinerea, in vitro. 55 f. Dissertação (Mestrado em Agronomia) Universidade Tecnológica Federal do Paraná. Pato Branco, 2010.

LORENZETTI, E. R.; MONTEIRO, F. P. I; SOUZA, P. E. I; SOUZA, R. J. I; SCALICE, H. K. I; DIOGO JÚNIOR, R. I; PIRES, M. S. O. I. Bioatividade de óleos essenciais no controle de Botrytis cinerea isolado de morangueiro. Revista Brasileira de Plantas Medicinais. Botucatu. v. 13, n. especial, p. 619 - 627. 2011.

MINITAB statistical software for Windows. [Computer program]. Version 14.0. Pennsylvania: Minitab Inc.; 2003.

SCHWAN-ESTRADA, K. R. F.; STANGARLIN, J. R.; CRUZ, M. E. S. Uso de extratos vegetais no controle de fungos fitopatogênicos. Revista Floresta, Curitiba, v. 30, p. 129 - 137, 2000.

PERINI, V.; DE CASTRO, H.; SANTOS, G. dos; CHAGAS JÚNIOR, A.; CARDOSO, D.; AGUIAR, R.; SOARES, A. Efeito de extratos vegetais na inibição do crescimento micelial de Pyricularia grisea. Journal of Biotechnology and Biodiversity, Tocantins, v. 4, n. 1, p. 70 - 77, 2013.

QUIRINO, V. F.; SZEREMETA, B.; GRIGOLETTI JR., A.; AUER, C. G. Efeito do extrato aquoso de folhas de seis espécies florestais sobre a germinação e crescimento micelial de Cylindrocladium spathulatum e Colletotrichum sp. Summa Phytopathologica, Jaguariúna, v. 26, n. 1, p. 141, 2000.

VENTUROSO, L. R.; BACCHI, L. M. A.; GAVASSONI, W. L.; CONUS, L. A.; PONTIM, B. C. A.; BERGAMIN, A. C. Atividade antifúngica de extratos vegetais sobre o desenvolvimento de fitopatógenos. Summa Phytopathologica, Botucatu. v. 37, n. 1, p. 18 - 23. 2011. 